Article

\title{
A Sketch on Daisaku Ikeda as a Jamesian Psychologist of Religion
}

\author{
Chae Young Kim \\ Religious Studies, Sogang University, Seoul 04107, Korea; chaekim@sogang.ac.kr
}

Received: 10 October 2019; Accepted: 31 October 2019; Published: 2 November 2019

\begin{abstract}
This essay attempts to determine whether Daisaku Ikeda can be seen as a Jamesian psychologist of religion. Concerning the development of this essay, it first focuses on a common concern that exists if we look at the work of William James and the Psychology of Religion in terms of how it exists as a distinct movement and how it is related to Ikeda's perception of religion within a secular world. Next, this essay articulates his notion of self and the role of mediating symbols as this exists, especially in religion, in discourse, and in the arts in correspondence and relation to James' Psychology of Religion. Finally, this essay critically raises questions that point to further developments as regards the thesis of this article.
\end{abstract}

Keywords: Psychology of Religion; William James; Daisaku Ikeda; religious healing; religious conversion; lesser self; greater self; religious experience

\section{Introduction}

Daisaku Ikeda (born 2 January 1928) is the third president of Soka Gakkai, a new religious movement (NRM) that originated in Japan in 1930. Ikeda's life and work are rich and can be studied from various perspectives. However, upon surveying the research materials that exist on Ikeda in and outside Japan, it appears that not a single essay has attempted to speak about him as essentially a psychologist of religion. Likewise, the present research trends do not seem to cover how Ikeda refers to the foundational works in Psychology of Religion, such as those of William James (1842-1910) (Wilson and Ikeda 2008, pp. 209-11). In this sense, this essay differs from other general sketches that have sought to describe Ikeda through the use of a list of familiar titles: Ikeda as the religious founder of a NRM (Inoue 1991; Reader 2006, pp. 141-54; Shimazono 2004; Miller 2004), as a Buddhist philosopher, as an educator, as a thinker, as a poet, as an artist, as a peace maker, as a facilitator of intercultural dialogue, as a global promoter of world citizenship, as the founder of a religious political party, and even as a Protestant lay Buddhist who can be seen as a kind of modern 'Martin Luther' within Buddhism (Seager 2006, p. 130), although, admittedly, in these diverse sketches, psychological elements are suggested and implied.

This essay attempts to determine whether the title of psychologist of religion can be properly ascribed to Ikeda. Regarding the development of this essay, it first focuses on a common concern that exists if we look at the work of William James and the Psychology of Religion in terms of how it exists as a distinct movement and how it is related to Ikeda's perception of religion within a secular world. Next, this essay articulates his notion of self and the role of mediating symbols, as this exists, especially in religion, in discourse, and in the arts in correspondence and relation to James' Psychology of Religion. Finally, it critically raises questions that point to possible further developments as regards the thesis of this article. 


\section{A Common 'Focal' Concern: Religion in a Secular World}

This section analyzes three equivalences or overlaps that exist between the Psychology of Religion proposed by William James in the Gifford Lectures of 1901-1902 and the concern that we find in Ikeda when he speaks about religion in our secular world. Prior to that, it is necessary to briefly recount the contribution of James to the field of Psychology of Religion and how these ideas can possibly resonate with Ikeda's own psychology of religion.

\subsection{William James and His Psychology of Religion}

Most modern academic disciplines, including Religious Studies, Sociology, Linguistics, Archeology, Anthropology, were originally formed in the universities of Europe. However, the Psychology of Religion is an exception, since it originally arose as an academic discipline in the late nineteenth and early twentieth centuries in New England, the United States (Touless 1971, pp. 1-2; Beit-Hallahmi 1977). Unlike other modern academic disciplines, to study Psychology of Religion, it was necessary for most students and researchers (including Europeans) to go to the United States. In the early period, a number of East Asian scholars in the field of the Psychology of Religion went to the United States for their higher studies. Returning to their home countries after their studies, they played a crucial role in the development of Religious Studies in relation to the Psychology of Religion (Sato 2005, pp. 52-62) ${ }^{1}$ until the Sociology of Religion emerged as a dominant interest in the 1980s and 1990s (especially in Japan). Their contributions were regional as the translation of psychological terms and concepts by Japanese psychologists exercised an influence on the world of the Chinese academics (Blowers 2000, pp. 1433-36).

The Psychology of Religion that inspired those East Asian scholars was shaped as a new discipline by William James (1842-1910) and his former student, Granville Stanley Hall (1844-1924). The title 'Psychology of Religion' was coined by Hall (Hall 1923, p. 356) but the spark which ignited interest in this new discipline came from William James. James' Gifford Lectures (which were later published as the seminal text The Varieties of Religious Experience: A Study on Human Nature) gave momentum to the Psychology of Religion, which soon became regarded as a new discipline within the academic world. Both James and Hall emphasized an in-depth psychological perspective in preference to the Analytic Psychology of Carl Jung. But, while James focused on a phenomenological analysis of the depth dimension that belongs to religious experience, Hall tried to proceed with a species of experimental research that encouraged a form of biological and developmental analysis prior to the birth of Developmental Psychology as a distinct discipline. Until the arrival and the delivery of the lectures of Sigmund Freud (1856-1939) and Carl Gustav Jung (1875-1961) at the twentieth anniversary Psychology conference organized and hosted by Hall at Clark University in 1909, the developments in the Psychology of Religion, directly or indirectly, had tapped into either of these two schools (Kim 2016).

In the works of James, there are two distinctive attempts at an in-depth understanding of Ikeda's interest in religion. First, James' Psychology of Religion tried to distinguish its own approach from a conventional approach to religious matters that was dominated by specific groups among a number of theologians and religious philosophers (James 2002, pp. 2-3). At that time, the study of religion was reserved to a theological context and therefore, it did not exist as an independent subject (Jordan 1986). In this situation, with the emergence of a scientific study of religion in Europe, James' Psychology of

1 Significantly, the key founder of Psychology in Japan, Yujiro Motora (1858-1912) first went to Boston University for his higher study of moral philosophy in 1883 but then in 1885, he moved to Johns Hopkins University for the study of Psychology, particularly under the guidance of Granville Stanley Hall, William James' first Ph.D student in Harvard University. At that time, he learned much about the Psychology of Religion from his supervisor. He received his Ph.D in 1888. He then returned to Japan and became the first Psychology professor in the department of philosophy at the Tokyo National University. His disciples would be appointed as key professors of Psychology and the Psychology of Religion in Japan. 
Religion in the United States sought to break with the current dominating ethos by making religious topics an object of study within an increasingly secular academic world.

However, in the scientific study of religion, this does not mean that the aim of engaging in a psychological study of religion is to eliminate religion within our human world. Its purpose and object differ entirely from the passionate discourse which comes to us from the contemporary scientism of thinkers such as Richard Dawkins and his followers. James attempted to create a more meaningful space for religious matters through an in-depth understanding of human nature in terms of how it is related to questions that emerge from within a scientific context. In other words, he rejected a way of thinking which insists on the mutually exclusive separation of religion and science. In this sense, James' Psychology of Religion was a revolutionary movement.

For the purpose of finding or constructing this bridge between religion and science, James focused on two major issues in the study of religion. First of all, James keenly realized that the religious discourses which occur within each religious tradition seem to come across as a 'babble' or a foreign language from the viewpoint of outsiders, whether they are religious or not. For the sake of fostering critical discussions about the relationship that exists between religion and science, he argued that religious language, in general, should be properly translated in such a way that it can be accessible to all persons (Taves 1999, pp. 271-74). To facilitate a communicative translation of religious languages, James believed that he could develop a new terminology in terms of Psychology and the kind of concepts that exist within Psychology (in his day, a new science). The most important terms that he cultivated as connotative carriers of meaning and which were richly embodied within his Psychology of Religion—terms such as 'self,' 'conversion,' and 'transformation' (James 2002, pp. 170, 231)—point to an order of meaning which belongs to the study of the psyche as a human science, such as we see in Jungian psychology (Jung 2014, p. 28). In this sense, James' Psychology of Religion can be identified as a comprehensive work of 'translation' that exists not only for religious people who belong to a given tradition but for other who do not participate in any given form of institutionalized religious tradition.

A second point with respect to James' Psychology of Religion and his study of religion is his engagement with the importance of the internal dimension which belongs to the life and practice of any given religion, particularly the human subject's own religious experience, as his Gifford Lectures book title indicates: The Varieties of Religious Experience. Unfortunately, James' emphasis has been categorized as if it existed as only one element or only one part of religion within the field of religious studies. Even well known scholar of religion Ninian Smart (1927-2001) tends to interpret it that way. Thus, he emphasizes that religion is akin to a species of organism which is composed of seven dimensions: the doctrinal, the ritual, the social, the ethical, the mythic, the experiential, and the material. He argues that religion has always exists throughout history as if it were a living being through the kind of combination which exists in these seven dimensions. However, the human subject's involvement in this process of combination is barely talked about (Smart 1999).

As a response, James' Psychology of Religion critically indicates that these dimensions cannot function by themselves but only through the kind of engineering that exists in the life and thought of the human subject. An emphasis on the religious experience of the human subject does not mean the ignorance nor the underestimation of other dimensions of religion. In fact, the human subject who experiences and lives out his or her spiritual tradition is the vital element for that multi-dimensional tradition to function as an organism. If the human subject does not engage him or herself in these dimensions of religion (whatever one's personal role), no given religion, from its birth and development to its possible demise, would be able to exist as a living organism. Therefore, as a consequence of this insight, the sustainability of religious tradition is ultimately grounded in the kind of living engagement with it that belongs to the life of a participant human subject. While initially, psychologists of religion tried to identify this process of 'living engagement' in terms of moments that are experienced in a possible series of moments, James interpreted them from within the perspective of a phenomenological and an in-depth psychological analysis that explicitly worked with psychological concepts and psychological relations: with concepts such as consciousness, the subconscious, and the self, and with 
relations given in a dynamic path of flow from the margin to the center or from the center to the margin in the life of the human psyche (James 2002, p. 144).

\subsection{Ikeda's Communicative Interest in Religion}

Similarly to James, Ikeda does not shy away from attending to the religious dimension of our human nature in order to respond to the key issues of modernity, whether in a secular context or in religious contexts beyond that of his own (Ikeda 1996, pp. 157-58). Although his focal point would not entirely overlap James' concern for the relationship between religion and science, no one can deny that, initially, Ikeda's interest also came from a number of science-related issues existing within our contemporary world. Unlike the advocates of scientism and secularism, Ikeda never avoided or bypassed religious issues in terms of how they relate to the problems of the present (Ikeda 1996, pp. 195-96). This sits at the core of Ikeda's philosophy: he thinks that if a religious dimension in any given situation and problem is not being seriously considered, then no solution will be meaningfully reached.

However, in effecting the global implementation of his convictions (Beyer 2006; Juergensmeyer 2006), Ikeda does not remain within a parochial religious framework which would be seen by many as a sign of religious extremism or attempted theocracy. Like James, he recognizes that problems will exist if you try to take the terminology and language of one person's religious tradition as the means whereby one communicates truths and meanings to other persons who live within another religious tradition. Although the mother tongue of his religious language is Buddhism, he has always tried to translate his terms into idioms and forms that could be understood not only by his own followers and adherents but also by those who could be regarded as outsiders (atheists included). This is a way of 'living engagement' to Ikeda.

Ikeda's 'translation' efforts are widely dispersed in his written materials: in his books, lectures, diaries, interviews, magazines, and other media. He avoids using technical religious language, preferring to use a conversational style in his writings and talks. Hence, in the light of this accessibility, his writings and talks 'easily' connect with his readers, dialogue partners, and audiences, irrespective of who they are or where they come from. In no crude way does he push his own spiritual affiliation on others, despite its rootedness in Nichiren Buddhism. Always, he tries to translate and to transpose his religious thoughts into a more communicable language for the benefit of other persons and for the sake of a bigger audience than among his SGI followers.

Ikeda appears to know 'instinctively' how his religious ideas should be seasoned in a way which nourishes the relation between a speaker and his or her listeners and enables him to exercise a formative influence. He is cognizant of a mutual position or a mutual relation that always exists between readers and listeners in any given audience. This skill has been evident not only within his published materials but also within the spontaneous conversations that he has enjoyed with many persons, both in Japan and in other countries. The more I meet his Korean followers and members, the more I come to realize that many stories about him have come from his many encounters with persons, often in an unexpected fashion. In many cases, especially in his university lectures, we can find three distinct skills which belong to the manner of his communication.

Firstly, in initiating a conversation or lecture, he tended to remind his audience in a sympathetic way that, in their own way, they are involved with issues and problems that have been the focus of his own life and works. By eliciting the awareness of listeners and by provoking their memory, he invited them or he called them into a form of mutual space. His talks did not belong to another world, they were not separated from concerns that people are currently experiencing and knowing, each in their own way. In doing so, Ikeda avoided creating an impression which emphasized the centrality of a speaker-a way of operating that we often find in much of our conventional discourse today. He avoided the way of speaking which came across as religiously 'crude' that exists among some religious groups or as a crude kind of secularism that rejects attending to the existence of a religious dimension in dealing with problems in our world today. 
Secondly, after initially engaging with his audience, Ikeda directly admitted to his listeners that his thought was fundamentally rooted in Buddhist religious culture. It was not necessary for him to refer to forms of Japanese Buddhism or to mention Nichiren Buddhism and the centrality of its scripture given in the Lotus Sutra. In the transition which he effected, he persuasively spoke about the relevance of Buddhism if we are to respond in a good way to a number of important global issues today. However, he avoided Buddhist jargon and the sophisticated doctrinal aspects, preferring to speak about the relevance of Buddhism in a way that could add to the meaning of his talks. In this context, his audience-whether they were religiously committed or not—did not feel put off in any kind of way.

Thirdly, Ikeda delicately articulated a comparative platform that referred to the religious or to the non-religious traditions of his audience in order to engage with his listeners more concretely than would otherwise have been the case. For example, in his talks in the United States, he referred to the importance of American Transcendentalism, in China, Confucianism, Buddhism or Taoism, and in Nepal, its own brand of Buddhism. He also focused on the specific legacies which belong to globally famous educators, philosophers, and artists who came or who had lived in other countries. In India, he referred to Mahatma Gandhi and in Italy, Brazil, Mexico, Russia, France and Spain, other representative artists, thinkers, and painters. Through comparative talks, he tried to build a rapport: his religious concerns were not far from the kind of essential messages which existed in the religious traditions, the cultures, and the civilizations that belonged to a given audience.

Through the delicacy of his interpretative thinking and expression, Ikeda articulated how, in the human subject, there exists momentous inner struggles that are germane to the birth and the development of a religious tradition, a culture, or a civilization in our human history. He did not simply praise them by using flowery external expressions. Instead, he fundamentally grasped the inner experience of human struggles as necessarily the locus of the soul or the spirit within the lives of his audience and SGI members. He thought that this inner awakening experience of the soul within his audience was identical with the growth and the evolution of the human condition in general (Ikeda 1996, p. 47).

Ikeda's engagement with the kind of inner experience which exists in an in-depth understanding of our humanity is clearly akin to James' academic interest and concern with the importance of religious experience in formulating a deeper understanding of human nature. The subtitle of his Gifford Lectures as 'A Study on Human Nature' speaks to this point. Hence, in the materials that Ikeda used in his encounter with other persons, he manifested a kind of mutual participation that is so essential if we are to have any progress in understanding how we have evolved as human beings in the context of our lives. A kind of religious experience or a kind of religious awakening emerges as, evocatively, it proceeds from a kind of dialectic which exists between the religious soul of a sympathetic speaker and that of an attentive listener.

\section{Self and Mediating Symbols}

Here, in indicating the concrete equivalences that exist between James' Psychology of Religion and Ikeda's understanding of religion, I would like to examine the depth of Ikeda's psychological 'translation' within the context of his religious language. In so doing, I focus on two key constituents that exist in an evolving way in Ikeda's Psychology of Religion.

\subsection{Notion of Self}

The most fundamental constituent in Ikeda's Psychology of Religion is the notion of self from which, as the basic root, his whole religious thought and vision have arisen and evolved. He was not trained in Psychology and he never tried to refer to himself as a psychologist. Yet, he seemed to know that, among other modern academic disciplines, better than any other disciple, the study of Psychology provided the best terms and concepts (Wilson and Ikeda 2008, pp. 212-13) if one was to translate the notion of the self in a way that could lead to its better understanding and identification. 
Nevertheless, admittedly, Ikeda did not believe that every psychology could be regarded as a proper source for terms that could be used to effect a communicable translation of his thought and vision in our contemporary world.

Ikeda manifested his sympathy primarily with regard to a school of Psychology that could dig into an inner and an outer transcendent tendency that inherently belongs to the human mind in properly characterizing it (Ikeda 1996, p. 161). Most especially, he referred to two psychologies in his talks. The first is Depth Psychology, in which we try to understand a hidden unconscious realm which is other than our conscious psyches and which, in a way, transcends it. The other psychology is Transpersonal Psychology. It attends to a transcendent supra-conscious realm which exists beyond the personal and the conscious dimensions of our psyches. Within the first kind of psychology, Ikeda specifically identified his thought with the Analytic Psychology of Carl Gustav Jung.

These two psychologies that Ikeda distinctively referred to are both related to James' Psychology of Religion. In point of fact, it should be noted that James' psychology played an important role in planting a seminal seed that led to the later development of Jung's Depth Psychology and also the later birth of Transpersonal Psychology. When Jung parted ways with Sigmund Freud and Freudian Psychoanalysis because he worked with a different understanding of religion, he came to realize that James' psychology was more compatible to his Analytic Psychology in embracing how, within our human nature, a fundamental religious element is to be found. In addition, in developing his typology of personality types, Jung appropriated James' theory of two personality types: the sick-soul type versus the healthy-minded type (Jung 1973, pp. 300-21).

James' Psychology of Religion was also related to the school of Transpersonal Psychology. He first coined the concept of 'transpersonal psychology' in his lecture notes (1905-1906) (Vich 1980, pp. 107-10; Taylor 1996, p. 26). Later, in the 1970s, this expression was appropriated by the movement of Transpersonal Psychology in the United States. In addition, James began to cultivate a form of psychological research that dealt with how, at the highest levels and as the center of Transpersonal Psychology, our human consciousness exists as a unifying spiritual potential, as a kind of operative potency. Hence, in the history of Transpersonal Psychology and among its many members, James was seen as its most important founder (Davis 2003, pp. 2-3, 6-21).

Hence, on the basis of these two connections, we can argue that a correspondence exists between James' Psychology of Religion and how Ikeda puts his religious thought into words and concepts. In particular, Ikeda sought to articulate his religious (Buddhist) thought in terms of the notion of self. In his exposition, he differentiates the notion of self into two selves (Ikeda 1996, p. 161). The first is identified as the greater self and the second, the lesser self. Sometimes, he noted that the lesser self is to be equated with the ego of our minds. In talking about their relationship, he seemed, at times, to separate them, although he also knew that they were not separated and fragmented but, in fact, deeply intertwined within the life of our human minds.

Ikeda thinks that our mind primarily operates through diverse relationships that exist between the greater self and the lesser self in the context of our human lives. The performance of all human life (whether individually or collectively) proceeds according to a mutual operation of the greater self to the lesser self and vice versa. No human life can exist without this operative process.

In addition, Ikeda articulated this operative process in terms of how it is related to the locus of both the greater self and the lesser self in the context of a topographical sense of mind (Ikeda 1996, pp. 8-10). He seemed to grasp the fact that the two transcending vectors that belong to the greater self exist with respect to the lesser self. The first vector is directed towards an inner dimension that exists beyond the lesser self. The greater self is seen to exist as the foundation of the lesser self. The second vector is directed towards an outer dimension which exists beyond the lesser self. Both vectors of the greater self are commonly oriented to the transcending source of both the inner and outer realms which exist beyond the being of the lesser self. The relationship between the greater self and the lesser self seems to resemble that of mother and child. A child can only properly grow in response to the mother's nurture. The greater self is like the matrix which bears the seed of the lesser self and which 
nurtures it in its growth. Hence, the lesser self can always renew itself through the nurturing tap which exists at its root within the greater self.

Ikeda argues and underlines the fact that this organic relationship between the two selves is something which lies at the foundation of individual and collective life in the context of our human religious traditions and civilizations. However, he also recognizes that our modern human history cannot proceed solely on the basis of the organic relationship which exists between them since, continuously, the lesser self is separating itself from its matrix which exists as the greater self. This situation endures and eventually leads to an ongoing devaluation of the greater self. As a result, this fragmented situation of the self begins to lead to a modern specification of consciousness which is willing, somewhat blindly, to accept rationalism and scientism as modern 'ideologies' that exist in a way which transcends the rational and scientific values which exist within our contemporary life (Ikeda 1996, p. 125).

Ikeda's critical point about the fragmentation of the modern self is identical not only with James' view but also with Jung's and with a transpersonal notion of the self. James' wider or subliminal self (James 2002, p. 508), Jung's self beyond the ego, and the supra-self of Transpersonal Psychology can be seen to be equivalent to the greater self that we find in Ikeda's notion of it. They all commonly emphasize the value of recovering from a fragmented consciousness of self that is predominant today and the value of moving towards a whole self that possibly exists. For both James and Jung, and also for Ikeda when he refers to the Buddha nature, the process of recovery fundamentally embodies a reconnection of religious and spiritual dimensions in the context of moving toward a deeper, a wider, and a fuller life which would belong to the life of a transcending self.

\subsection{Mediating Symbols}

However, the reconnection of the lesser self to the greater self cannot be attempted if, by means of oneself or with others, one does not seek to build a bridge between the selves in certain life situations. The bridge functions as a symbol playing a mediating role between one's two selves. Human history cumulates and it emerges through varieties of symbols that mediate a reconnection that can possibly exist between these two selves.

Ikeda pays special attention to three mediating symbols that have functioned as major catalysts in human history. They are found in religion, in dialogue, and in the arts. In his judgment, they are widely seen by other persons as symbols which affect how the two selves can encounter each other. However, in the mediation which occurs, these symbols best lead us toward cosmic life experiences as these things emerge for us at times when the greater and lesser selves connect with each other.

Ikeda emphasizes the fact that this experience exists as our 'human revolution'. This revolution refers to the radical transformation of a human subject. It is equivalent to a species of conversion experience and it can happen within any human life context. This human revolution shows itself psychologically through a kind of radical change which occurs as the lesser self moves from the center of things toward the margins and, conversely, as the greater self moves from the margins toward a center stage.

\subsubsection{Religion}

Ikeda thinks that religion provides a fundamental and a powerful platform for the human subject if one's lesser self is to experience a re-orientation that turns this self toward the being of the greater self. However, if religion does not function properly in human life, as we seem to be seeing in our world today, it will not be helpful for us in achieving that re-orientation. Here, Ikeda specifically points to the problem of dogmatism in the world of religion (Ikeda 1996, p. 196). He thinks that if dogmatism is not functioning properly, it cannot guide us as human subjects if we want to move forward in order to encounter the greater self. We will be trapped into a religious parochialism of individuals or a parochialism of a collective lesser self. 
This negative aspect leads to many ugly things: religious violence, religious discrimination, and a distorted notion of human rights within the story and the history of religion and, at the moment, this is still creating many problems in the modern East. As the consequence of the negative experience of religion that is ceaselessly occurring around our world today, to what is cited as 'common faith' in John Dewey's Terry Lecture at Yale University in 1933-34, Ikeda gives a greater measure of attention (Ikeda 1996, p. 158).

In his lecture, Dewey distinguishes between an institutionalized form of 'religion' and a synthetic creative experience: 'religious', which, when given to us, embodies and embraces the fullness of the depth dimensions that belong to how we fully exist as human subjects (Dewey 2013, p. 23; Garrison et al. 2014; Ikeda Center 2010). While the former ('religion') pertains to the realm and the order of visible individual religions, the latter (the 'religious') refers to what can happen in any context, whether in the realm of democracy, human rights, education, the arts, social welfare, community gatherings, nature environments, etc. Dewey expands on this by noting that the momentary experience of the deeper dimension which belongs to each of us as a human being, regardless of where it happens, can be interpreted as embodying the meaning of 'religious' as an adjective. In other words, Dewey suggests a new interpretation of 'religion' not on the basis of any kind of conventional dualism but on the basis of an adjectival dimension which exists across all realms of human life.

Ikeda agrees that the concept of 'religion' as a noun tends to emphasize and to defend something which exists as particularity or individuality while the adjectival notion of 'religious' tends to be more concerned with experiences of commonality and universality (Ikeda 1996, pp. 158-59). He finds that the adjectival notion corresponds to his thought on religion in terms of a momentary connection between the lesser self and the greater self. In particular, he grasps the fact that momentary 'religious' experience cannot be limited to the dualistic realm of 'religion'. This religious life is not too concerned with attending to the institutionalized individuality of any given religion. It is concerned more with a kind of common or universal experience which exists beneath or beyond any given individuality or any given particularity which exists within any religion or other forms of life.

Here, we can also find a fundamental commonality between Ikeda's interpretation of religion and the depth Psychology of Religion of James and Jung. They all do not agree on what is meant by a conventional dualistic understanding of religion. Instead, they tend to emphasize the good as referring to a more comprehensive 'natural' interpretation of religion in human life. With respect to the world of religion, James identifies many constituents: prayer, faith, belief, ritual, fellowship, hymns, and other elements which exist as expressions that come from the mediation of a subliminal self and also as a fundamental platform for the human subject to move forward to an encounter with the subliminal self.

In addition, James did not believe that this platform is limited to the being of an institutionalized religion (James 2002, pp. 2-3). For him, at other times, apart from visible institutionalized elements that belong to a given religion, beauty in nature and culture, human fellowship and friendship, and other things which include the practice of political justice and the process of democratization in a political order-all these things can be identified as expressions of how a human subject, individually or collectively, encounters a subliminal self. These expressions accordingly also serve as a platform for later followers who can be variously identified as viewers, listeners, or as readers and those who exist as diverse participants-all enjoying an originator's expressions given through painting, music, sculpture, ethics, philosophy, drama, and sciences within the fabric of our human civilization and culture.

\subsubsection{Dialogue}

In Ikeda's life and works, dialogue exists as an indispensable component if we are to engage in the business of human life (Ikeda 2017, pp. 89-93; Bosco et al. 2009, p. 172; Cox and Ikeda 2009). It is an important symbol that, the importance of which in his judgment, all great peoples of wisdom in the East and the West should emphasize if they are to engage with things of this world. Most importantly, two distinct models of dialogue have existed in human history. In the intellectual life of Socrates, dialogue was more powerful and of greater interest than violence. This is evidenced when we look at 
how Socrates approached his own death (Ikeda 1996, p. 173). A similar spirit of dialogue can be found in how Buddha faced death on his deathbed (Ikeda 1996, p. 174). Like Socrates, Buddha asked his disciples not to stop asking questions; he continuously engaged them in his conversations with them.

According to Ikeda, dialogue is not limited to a small number of great personages. It is open to everybody. Human life without dialogue cannot be maintained and kept. It is the 'path humanity needs to travel' (Bosco et al. 2009, p. 3). Even if a person is alone and is living apart from others, as subjects, we are engaged in many dialogues through our memories of the past. We remember our own past and make dialogue with its compositions within a context conditioned by our present surroundings and also by our future expectations and our hopes about things to come. Yet, despite our sense of duration and time as we think about these things, the past, present and future, which emerge through our engagement in various forms of dialogue, are commonly identified in terms of a momentary experience that occurs in the 'here and now.' In this sense, physically, the world that we sense seems to exist as one world, but in the context of dialogue, it exists as an evolving thing. It moves into an unlimited number of worlds that are continuously being filled with new emergent partners. This aspect exists not only in individual life but also in collective life. Hence, the core of dialogue is not simply to encounter people in a direct way within an immediately existing physical world but, instead, it is to encounter them in terms of their emergent inner worlds (Smith 1959).

Ikeda tried to communicate this point through ceaseless dialogue with many different professionals: with historians, philosophers, educators, politicians, scientists, theologians, sociologists of religion, artists, and others, such as Arnold J. Toynbee (British historian and philosopher), Henry Kissinger (American politician), Mikhail Gorbachev (Soviet politician), Chingiz Aitmatov (Soviet and Kyrgyz author), Tu Weiming (Chinese-born American ethicist and philosopher), Harvey Cox (American theologian), and Bryan R. Wilson (sociologist of religion). His efforts were akin to how he related to collectivities, groups and ordinary people that he happened to meet. By his direct engagement in dialogue, he put his best efforts into trying to understand better the inner world of his dialogue partners and from there, move toward thinking about the possible emergence of an authentic world which would exist as a cosmos. This all derives from how a lesser self reconnects with the being of a greater self through a kind of mutual self-mediation which exists when, in conversation and through dialogue, Ikeda and the others become partners and friends.

Ikeda thinks that dialogue should encourage and guide a human subject. Whether as an individual or as part of a collective, one wants to dig into a dimension of life which transcends the being of the lesser self. Good dialogue should continuously remind a human subject about the presence of a greater self. The modern self is so obsessed with the lesser self that it seems to forget the whole dimension of self (Ikeda 1996, p. 125). This feature of a modern stranded self exists not only in our individual lives but also in human collective life. It has been already diagnosed as a condition of illness which is to be equated with the problem of ego inflation. If this ego is to undergo any kind of renewal, it should not concern itself with how it has emerged in modern times but with how it can be healed to recover an entire dimension of self that has been neglected and forgotten. Ikeda clearly highlights this problem and he emphasizes the fact that dialogue exists as a healing tool for a fragmented sick self to be turned into a happy, whole self.

In a real sense, Ikeda is almost playing a role which has traditionally belonged to psychoanalysts and psychotherapists who engage in dialogue with patients in order to identify problems and to encourage healing in diagnostic and analytic contexts (Ikeda 1996, pp. 168-69). No matter what the situation, Ikeda tries to engage in a mutual form of depth dialogue with participants in order to identify problems which plague both individuals and groups and to encourage their healing through a re-connective process which reveals how the lesser self of a human subject is fundamentally rooted in the being of a larger, greater self. 


\subsubsection{Arts}

In Ikeda's life, the human arts are regarded as a mediating symbol which is equivalent to the kind of mediation which exists in religion and dialogue (Ikeda 2017, pp. 59-61). While Ikeda appears to be a sympathetic observer of the human arts, he also participated in the being of his own artistic expressions. He was gifted by artistic desires which expressed themselves in poems, novels, and music. In addition, on the basis of his own observations and his creative abilities, he could deeply understand why the arts operate effectively in ways which can help human subjects to have a reconnecting experience of the lesser self to the greater self. He explicitly emphasizes the fact that artistic creative activities must exist as a process which embodies an artist's experience and sense of cosmic life (Ikeda 1996, pp. 4-5).

In their own lives, artists journey into the wider and the deeper world of the universe. Comparatively speaking, ordinary artistic observers are not to be regarded as artistic originators, although they embark on a similar journey as they, depending upon the degree of their experience, move from their private worlds into the greater world that an artist expresses. Ikeda believes that these two journeys of the artist and the observer are equally important in the sense that both can move forward to a momentary experience of cosmic life. In this sense, he does not speak about art for the sake of art but only according to the belief that the arts are very worthwhile as mediating symbols if we are to move toward an experience of the greater self (Ikeda 1996, pp. 8-10).

Because of these beliefs about art, most of Ikeda's writings and speeches are full of diverse artistic references, not only to his poems but also to well known artistic works of various poets, novelists, painters, musicians, and artistic philosophers in history. He really knows that the arts have a unity or a reconnecting power which drives us as human subjects, irrespective of whether we are artists or not. Through the arts, we are led to experience a world beyond our own ordinary world in a form of cosmic life.

Here, with regard to the arts, we find in Ikeda another connection with James' and Jung's Depth Psychology. James was also concerned about the function of the arts as mediating symbols if we are to experience a subliminal self which transcends an ordinary conscious dimension (James 2002, p. 501; Capps 2015, pp. ix-x). He frequently talked about the arts with his famous novelist younger brother, Henry James. In addition, he was once fully engaged in painting and wanted to become a painter in his earlier days.

Similarly, Jung also spoke about the function of the human arts as mediating symbols. He championed the value and the good of studying symbols. For him, symbols fall into two types: natural symbols and cultural symbols (Jung 2014, p. 28). Natural symbols emerge in dreams while cultural symbols emerge and exist through the arts, in cultures, in religions, and through other human activities. For him, all symbols reveal the human subject's depth experience of self although, in addition, a collective unconscious exists beyond a conscious realm.

\section{Tentative Conclusions}

This essay attempts to draw my sketch about Daisaku Ikeda within the frame of a Psychology of Religion, particularly in terms of William James' Psychology of Religion. The similarities between Ikeda's communication skills and James' psychological concerns, their notions of self and the role of mediating symbols between Ikeda's dialectic understanding about how the two selves relate in a way pointing to cosmic life, the idea that grounds his notion of human revolution, and James' interpretation of religious conversion are undeniable.

However, in this context, one question should be raised on Ikeda's optimistic worldview. The more his works are examined, the greater they tend seemingly to give the impression that, as human beings, we can surmount all kinds of human conditions, no matter how impassably challenging they are. In Ikeda's work, there is an emphasis that our mental power exists as a positive and "almighty" force. There is no human suffering and evil that we cannot overcome. Although Ikeda himself faced many difficulties dealing with the deaths of his brother and his mentor, he did not seem to reveal much about 
any kind of self-surrender that would exist through experiencing such existential anxiety and despair. The image that we have of him is as having a strong will that nothing can challenge.

Such an image corresponds to James' image of the healthy-minded person. In his own way, Walter Whitman is also such a person in the context of his Psychology of Religion: so optimistically does the person praise human life that he is not able to see where shadows exist on the other side of it (Tesstore 2008, pp. 497-98). He emphasizes the fact that persons who are obsessed with this dimension of life (as if it existed as an empirical reality) tend to have big problems. Whitman's point resembles Ikeda's attitude toward life. In dealing with the world, a human subject lives best through engaging in some form of continuous self-transformation of their life attitudes. Ikeda does not seem to emphasize the value or the good of any type of radical self-transformation. This type of self-transformation is sudden conversion experience that was taken by St. Paul and by St. Augustine and also by Ikeda's mentor, Josei Toda (1900-1958). In his life, while being imprisoned, Toda had an extreme radical type of conversion experience irrespective of his will. St. Paul, St. Augustine, and Toda all commonly tried to overcome their existential anxiety and despair and they could not do it without experiencing a radical invasion that came as a totally sudden experience in the context of their individual lives (regardless of how it was identified with some form of ultimate reality). However, James believed that this kind of transformation as conversion could be found more in the life of the sick soul than in the life of the healthy-minded. While a sick soul needs a 'twice born' experience for his or her conversion, the healthy-minded does not. The healthy minded person tends to think that natural life itself is sufficient for the transformation of one's life. One does not need any other power except one's own personal power. In contrast, however, the sick-soul person tends to think that sudden transformations as conversions are radically formed within a kind of self-surrender which knows that these good changes cannot be effected by means of one's personal will.

Hence, we can tentatively conclude this sketch about Ikeda in two ways. The first is that the emphasis on radical conversion was not a crucial issue in Ikeda's own life and work, even though he may have had such experience. Our human change exists, instead, as an extension or a prolongation if we work from a natural and a supernatural perspective on how, as human beings, we normally change and have transformations in our lives and how these can exist as conversions. The second is simply that Ikeda did not seemingly have a radical experience similar to that which was experienced by Josei Toda. In this case, taking into account the close relationship and strong influence between the master and the student, for his fuller development as a Jamesian psychologist of religion, another study about how Ikeda related to his mentor Josei Toda and his radical experience is necessary and worthwhile.

Funding: This work was supported by Global Research Network program through the Ministry of Education of the Republic of Korea and the National Research Foundation of Korea (NRF-Project number) (NRF-2017S1A2A2040811).

Conflicts of Interest: The author declares no conflicts of interest.

\section{References}

Beit-Hallahmi, Benjamin. 1977. Psychology of Religion 1880-1930: The Rise and Fall of a Psychological Movement. In Current Perspectives in the Psychology of Religion. Edited by H. Newton Malony. Michigan: William B. Eerdmans Publishing Company.

Beyer, Peter. 2006. Religion in Global Society. Abingdon: Routledge.

Blowers, Geoffrey. 2000. Learning from Others: Japan's Role in Bringing Psychology to China. American Psychologist 55: 1433-36. [CrossRef] [PubMed]

Bosco, Ronald A., Joel Myerson, and Daisaku Ikeda. 2009. Creating Waldens: An East-West Conversation on the American Renaissance. Cambridge: Dialogue Press.

Capps, Donald D. 2015. The Religious Life: The Insights of William James. Oregon: Cascade Books.

Cox, Harvey, and Daisaku Ikeda. 2009. The Persistence of Religion: Comparative Perspectives on Modern Spirituality. New York: I. B. Tauris.

Davis, John. 2003. An Overview of Transpersonal Psychology. The Humanistic Psychologist 31: 6-21. [CrossRef] Dewey, John. 2013. A Common Faith. New Haven: Yale University Press. First published 1934. 
Garrison, Jim, Larry Hickman, and Daisaku Ikeda. 2014. Living as Learning: John Dewey in the 21st Century. Cambridge: Dialogue Path Press.

Hall, Granville Stanley. 1923. Life and Confessions of a Psychologist: An Autobiography. New York: D. Appleton and Company.

Ikeda, Daisaku. 1996. A New Humanism: The University Addresses of Daisaku Ikeda. New York: Weatherhill.

Ikeda, Daisaku. 2017. Hope is A Decision. Santa Monica: Middleway Press.

Ikeda Center. 2010. Harvey Cox: Faith beyond Fear and Hierarchy. Conducted by Masao Yokota. October 8. Available online: https://www.ikedacenter.org/thinkers-themes/thinkers/interviews/cox (accessed on 14 April 2019).

Inoue, Nobutaka. 1991. Recent Trends in the Study of Japanese New Religion. In New Religions. Edited by Nobutaka Inoue. Translated by Norman Havens. Tokyo: Institute for Japanese Culture and Classics, Kokugakuin University.

James, William. 2002. The Varieties of Religious Experience: A Study in Human Nature. New York: Dover. First published 1902.

Jordan, Louis Henry. 1986. Comparative Religion: Its Genesis and Growth. Atlanta: Scholar Press. First published 1905. Juergensmeyer, Mark. 2006. Thinking Globally about Religion. In The Oxford Handbook of Global Religions. Edited by Mark Jurgensmeyer. New York: Oxford University Press.

Jung, Carl Gustav. 2014. Archetypes of the Collective Unconscious. The Collected Works of C.G. Jung. Princeton: Princeton University Press, vol. 9. First published 1960.

Jung, Carl Gustav. 1973. Psychology and Religion: West and East. Edited by Herbert Read, Michael Fordham and Gerhard Adler. Translated by Richard Francis Carrington Hull. The Collected Works of C.G. Jung. Princeton: Princeton University Press, vol. 11. First published 1969.

Kim, Chae Young. 2016. Carl Gustav Jung and Granville Stanley Hall on Religious Experience. Journal of Religion and Health 55: 1246-60. [CrossRef] [PubMed]

Miller, David. 2004. Soka Gakkai. In New Religions: A Guide: New Religious Movements, Sects and Alternative Spiritualities. Edited by Christopher Partridge. Oxford: Oxford University Press.

Reader, Ian. 2006. Japanese New Religious Movements. In The Oxford Handbook of Global Religions. Edited by Mark Juergensmeyer. New York: Oxford University Press.

Sato, Tatsuya. 2005. The Early 20th Century: Shaping the Discipline of Psychology in Japan. Japanese Psychological Research 47: 52-62. [CrossRef]

Seager, Richard Hughes. 2006. Encountering Dharma: Daisaku Ikeda, Soka Gakkai, and The Globalization of Buddhist Humanism. Berkeley: University of California Press.

Shimazono, Susumu. 2004. From Salvation to Spirituality: Popular Religious Movements in Modern Japan. Melbourne: Trans Pacific Press.

Smart, Ninian. 1999. Worldviews: Cross-Cultural Explorations and Human Beliefs. New York: Pearson.

Smith, Wilfred Cantwell. 1959. Comparative Religion: Whither-and Why. In The History of Religions: Essays in Methodology. Edited by Mircea Eliade and Joseph M. Kitagawa. Chicago: University of Chicago Press.

Taves, Ann. 1999. Fits, Trances, and Visions: Experiencing Religion and Explaining Experience from Wesley to James. Princeton: Princeton University Press.

Taylor, Eugene. 1996. William James and Transpersonal Psychiatry. In Textbook of Transpersonal Psychiatry and Psychology. Edited by Bruce W. Scotton, Allen B. Chinen and John R. Battista. New York: Basic Books.

Tesstore, John. 2008. The "Sky-Blue" Variety: William James, Walt Whitman, and the Limits of Healthy-Mindedness. Nineteenth-Century Literature 62: 493-526. [CrossRef]

Touless, Robert H. 1971. An Introduction to the Psychology of Religion. Cambridge: Cambridge University Press.

Vich, Miles A. 1980. Some Historical Sources of the Term "Transpersonal.". Journal of Transpersonal Psychology 20: 107-10.

Wilson, Bryan, and Daisaku Ikeda. 2008. Human Values in a Changing World: A Dialogue. New York: I. B. Tauris.

(C) 2019 by the author. Licensee MDPI, Basel, Switzerland. This article is an open access article distributed under the terms and conditions of the Creative Commons Attribution (CC BY) license (http://creativecommons.org/licenses/by/4.0/). 